Resenhas 
língua. São Paulo: Parábola, 2018. 200 p.

\title{
A linguística, o texto e o ensino da língua
}

\author{
Clézio Roberto Gonçalves** \\ Elaine da Fonseca Ramos**
}

O livro A Linguística, o texto e o ensino da língua, publicado, em 2018, pelo autor José Carlos de Azeredo, busca reafirmar a importância da palavra como base de qualquer ensino, uma vez que é na posse e no uso da língua que se reconhece o modo de ser do sujeito. Além disso, em todos os capítulos do livro, o autor demonstra que o texto é composto por palavras (objeto) e objetivo do ensino de língua materna.

José Carlos de Azeredo se doutorou em Letras em 1988 pela Universidade Federal do Rio de Janeiro. Lá, atuou nas atividades docentes de 1970 até 1996. Ainda exerce a função de professor associado de Língua Portuguesa na mesma universidade. No biênio de 1999-2000, coordenou o Mestrado em Língua Portuguesa. É pesquisador bolsista do CNPq. É coordenador do livro Escrevendo pela nova ortografia e autor da Gramática Houaiss da Língua Portuguesa e do Dicionário Houaiss de conjugação de verbos. Organizou os volumes Língua Portuguesa em Debate: conhecimento e ensino (Vozes) e Letras e Comunicação: uma parceria no ensino de língua portuguesa (Vozes). Publicou por Jorge Zahar Editor os volumes Iniciação

\footnotetext{
* Pós-doutor em Língua e Cultura (PPGLinC/UFBA). Professor Associado de Linguística Aplicada e Língua Portuguesa do Departamento de Letras da Universidade Federal de Ouro Preto (DELET/UFOP). Professor Permanente do Programa de Pósgraduação em Letras da Universidade Federal de Ouro Preto (POSLETRAS/UFOP). ORCID: https://orcid.org/0000-00034095-6683

** Universidade Federal de Ouro Preto (UFOP). Educadora. Mestranda em Letras: Estudos da Linguagem (UFOP). ORCID: https:// orcid.org/0000-0002-4139-4099
} 
à sintaxe do português (1990) e Fundamentos de gramática do português (2000).

O livro A Linguística, o texto e o ensino da língua foi publicado pela Editora Parábola, possui 200 páginas que são divididas em: Apresentação, 12 capítulos com subtítulos e referências bibliográficas.

$\mathrm{Na}$ apresentação, o autor menciona que o homem para viver em sociedade, necessita da palavra, ou seja, ela é indispensável. O valor da palavra vai muito além de ela ser um simples instrumento da linguagem, isto é, apenas para os seres humanos se comunicarem entre si. $\mathrm{O}$ fato de ela ser inerente ao homem, a linguagem não se explica em termos naturais. Ela tem fundamento no universo social, porque se integra a fenômenos culturais aprendidos no decorrer da vida.

$\mathrm{O}$ autor alerta que as pessoas tendem a tratar as palavras como algo armazenado na memória. Quando estão conversando com o outro, busca no arquivo da memória, a palavra adequada para a comunicação. Para ele, isso é proveniente da crença de que as palavras que usamos ao nos comunicar fazem parte de um mundo que organizamos como um conjunto de coisas, fatos e sensações. Isto quer dizer que, o material armazenado em nossa mente seria apenas reflexos do mundo em que vivemos e a linguagem funcionaria apenas como rótulos para representar os reflexos.

Em contrapartida, Azeredo argumenta que tal crença é falsa visto que a linguagem não é uma simples ferramenta e nem o espelho de um mundo de objetos e fenômenos que permeiam a consciência humana. Nossos textos não é um retrato fiel de nossas vivências de mundo, pois eles, quando criados, representam uma filtragem e modelagem dessas experiências 
que são manifestadas por meio da linguagem. Logo, em uma interação entre duas pessoas ou mais, o que importa não é o que está na em nossa cabeça, mas sim, o que o interlocutor entende mediante aos sinais que o outro produz.

Em relação ao ensino de língua materna, Azeredo argumenta que o importante é ensinar o outro em como manejar esses sinais, seja na elaboração de um texto, seja no entendimento ao texto da outra pessoa.

Para o autor, os debates sobre o uso e a reflexão sobre a língua em relação ao desenvolvimento e aperfeiçoamento das competências de compreensão e expressão não são novos. Perdura há muito tempo, por isso, o tema do livro não é novo. É mais um debate. É de bom senso compreender que nenhuma pessoa aprende a ler e a escrever estudando apenas gramática e fazendo exercícios de metalinguagem.

A reflexão sobre a língua é uma prática que a coloca como foco do processo de aprendizagem e desenvolve sobre ela um conhecimento tanto sobre a natureza humana quanto a vida dos homens em sociedade. Assim, o ensino de língua percorre todos os capítulos do texto.

No capítulo 1 A linguística, o texto e o ensino da língua: notas para um debate Azeredo apresenta que a Linguística, ciência da linguagem, desde 1960, incorporou o texto como objeto. Mediante isso, surgiu a Linguística Textual ou Linguística do Texto. Com o surgimento desse campo do conhecimento, muito tem contribuído para reduzir a distância entre o ensino e a pesquisa sobre língua. No Brasil, a Linguística volta seu olhar para o texto. Com isso, o texto é considerado uma unidade de análise linguística e que, para seu funcionamento ser realmente explicado, é importante considerar o papel das variáveis do 
evento comunicativo: "quem o enuncia, para que fim o faz, a quem o destina etc.” (AZEREDO, 2018, p.16).

Em relação ao ensino de gramática, o autor baseia-se nos estudos de João Wanderley Geraldi, por ser um destaque nos estudos linguísticos recentes no Brasil e tentar dar um novo rumo ao ensino de língua portuguesa. Para Azeredo, quando o autor Geraldi chega à seguinte conclusão "que a análise gramatical é inútil, ou pelo menos desnecessária, como estratégia para o ensino da língua." (AZEREDO, 2018, p.18) Azeredo discorda, pois para ele, é importante a pessoa conhecer e ter o domínio teórico e analítico da língua, visto que não tem como usar um objeto sem conhecê-lo. Azeredo contra o argumento de Geraldi afirma que “(...) ele revela uma concepção redutoramente utilitária do conhecimento" (2018, p.18).

Azeredo fala que muitos linguistas e educadores compartilham a ideia de que uma aprendizagem e prática de análise gramatical não tem influência no desenvolvimento da competência linguística do estudante. Eles pensam que a leitura e a escrita são habilidades aprendidas sem teorização, somente com a prática. Ainda para o autor, é sedutora a ideia de aprender sem teoria, ou seja, aprender com a prática, isto ocorre porque se confunde processo e produto em um modelo de aprendizagem.

Finaliza, concordando com os teóricos que defendem o ensino de língua materna que aborde o ensino da gramática, pois o conhecimento gramatical gera qualidade na leitura e no desempenho da comunicação. $\mathrm{O}$ autor deixa claro que, quando ele defende um ensino que tenha gramática, não quer dizer que, ela seja o centro do ensino, mas é necessária. Assim, Azeredo (2018, p.20) afirma que "quando alguém passa a entender como a língua se organiza para desempenhar suas funções, seguramente 
se torna muito mais apto a extrair significados de suas formas, seja como leitor, seja como enunciador".

O capítulo 2 Língua e Texto: o livro didático de português nos anos de 1960 e 1970, o autor inicia seu texto abordando a importância de duas palavras: política e cultura. Isto porque, em 1960, a população brasileira viveu um período de transformações políticas e culturais. Dentro desse contexto, as manifestações culturais do povo passaram a ser valorizadas.

Devido a tal mudança, os órgãos e agentes da educação foram impelidos a repensar os conteúdos, as estratégias e os objetivos da escolarização. Com isso, veio à liberdade dos educadores para ensinar principalmente os autores dos livros didáticos que passaram a poder seriar e selecionar os conteúdos a serem ensinados.

A produção do livro didático, em 1960, para uma melhor compreensão, o autor dividiu em dois momentos:

$\mathrm{O}$ primeiro momento, as transformações educacionais foram lentas principalmente o ensino de português que foi percebido por meio dos livros didáticos produzidos para o ensino secundário.

As obras marcantes referentes ao ensino de português que marcaram a época e foram largamente utilizadas em escolas do Rio de Janeiro foram "o Português básico (Editora Agir), de Adriano da Gama Kury; a série intitulada Português (Editora Francisco Alves), de Domingos Paschoal Cegalla; o Manual de Português para a $1^{\mathrm{a}}$ e a $2^{\mathrm{a}}$ séries ginasiais (Livraria São José), de Celso Cunha.” (p.23). Tais livros didáticos continham textos literários para que o professor iniciasse as aulas com uma leitura, entretanto, o ensino de gramática prevalecia. Ressalta-se que em aspectos linguísticos não havia muita diferença entre eles, mas 
em relação à seleção de textos, era bem notável.

O segundo momento, segunda metade dos anos de 1960, foi produzida uma “Antologia para o ensino médio de português" intitulada Rio de toda gente elaborada por Helena Godoy Britto, M. Cavalcanti Proença e M. da Glória de Souza Pinto. A proposta buscava o ensino da leitura e comentário dos textos. A grande novidade da obra conforme Azeredo (2018, p.25) argumenta era “(...) ostensiva preocupação em enriquecer a leitura dos textos mediante a observação e análise de seus procedimentos estilísticos, aí concebidos como recursos idiomáticos responsáveis pela ênfase expressiva que aumenta o rendimento informacional da mensagem.”. Apesar de a obra ser fragmentada e eclética, podia ser considerada um avanço importante para um ensino de língua focada no texto.

Mais tarde, a coautora da obra mencionada anteriormente, Maria da Glória de Souza Pinto, lançou uma série didática intitulada Português através dos textos, tendo como base o modelo experimental da obra coletiva de 1965. Em cada texto introdutório de uma unidade havia um questionário focado no rendimento da gramática, do vocabulário e dos procedimentos enunciativos.

No final da década de 1960 foram publicadas mais duas obras com a mesma linha de ensino da outras duas citadas anteriormente: Português através dos textos de Magda Soares, publicada por Bernardo Álvares, de Belo Horizonte, e à série intitulada Português da Editora Liceu, Rio de Janeiro, escrita por Domício Proença Filho e Maria Helena Duarte Marques. A obra de Magda Soares retomou a descrição gramatical, excluindo como estratégia, a exemplificação do texto base da unidade.

Em virtude a lei 5.692, de 1971, as diretrizes de ensino 
da língua tiveram mudanças, tornando a Língua Portuguesa uma área de estudo - comunicação e expressão - formada com educação física, educação artística e língua estrangeira como opcional.

Devido ao uso dos conceitos de informação e comunicação na época, as palavras contexto, código, mensagem, redundância e ruído tornaram-se palavras presentes no discurso não só acadêmico, mas também, no discurso didático do ensino de primeiro e segundo graus. Azeredo $(2018$, p.28) afirma que o ensino de língua passou a ter um conceito reduzido como “(...) língua passou a ser abordada como simples instrumento de comunicação e sua vitalidade, a ser medida pelos efeitos que alcançava na interação social.”

Com a presença marcante do termo comunicação no ensino de Língua Portuguesa, o termo texto foi trocado por comunicação nos títulos dos livros didáticos. Desse modo, os estudantes passaram a ter contato com os termos remetente, destinatário, código, mensagem etc.

Nas universidades, as abordagens estruturalistas da língua e da literatura começaram a perder espaço para a semiologia. A obra de destaque foi Linguística e poética de Roman Jakobson. Ela discriminava as seis funções da linguagem que correspondiam aos elementos da comunicação. Sendo assim, passou a ser uma nova abordagem da língua.

Nos anos de 1970, as três obras tidas como propostas inovadoras e atualizadas quanto ao embasamento linguístico e pedagógico são:

“(1) Comunicação/Expressão e cultura brasileira, 4 volumes, de Maria Helena Silveira (Petrópolis (RJ): Vozes);

(2) Comunicação/Expressão em língua nacional, 4 
volumes, de Amaro Ventura e Roberto Soares Leite (São Paulo: Companhia Editora Nacional);

(3) Português: treinamento e criatividade, 4 volumes, de Carlos Maciel, Fábio Márcio, José Starling e Milton do Nascimento (Belo Horizonte: Editora Vigília)" (2018, p.30)

O autor destaca que a obra um estava alinhada com a obra Rio de Toda Gente, o texto era o motivo e propósito do ensino de língua. A obra dois dava enfoque da língua como o código, tendo como objetivo apresentar que por meio da linguagem tudo era possível ao homem. A obra três para o autor é "esta obra me parece a mais ambiciosa - mas não necessariamente a mais inovadora - de quantas examinei”. (AZEREDO, 2018, p.32) Isto porque, nos volumes destinados aos professores, o foco do ensino de língua era voltado para a Teoria da Comunicação, Roman Jakobson, para o estruturalismo e gerativismo norteamericanos.

O capítulo 3 Construção e funcionamento dos textos: conceitos básicos aborda uma reflexão que gira em torno da prática da interação humana sendo mediada pela linguagem verbal, pois seus sinais funcionam como sentidos compartilhados entre os seres e organizados em sistemas. Os sentidos são construídos na interação das pessoas umas com as outras e com o mundo que as rodeiam.

$\mathrm{O}$ homem se comunica por meio da língua. $\mathrm{O}$ ato comunicativo por meio da língua denomina-se discurso. O texto é uma manifestação real do discurso através de uma linguagem. As informações e conteúdos que circulam entre as pessoas são através dos textos orais ou escritos.

Em relação ao contexto e o contrato de comunicação, para o autor, a comunicação entre os homens sempre se dá por meio 
de um contexto sociocomunicativo. O discurso escolhido na interação entre as pessoas é fruto dos condicionamentos mental e psicológico. Além disso, o ambiente físico e social também influencia. Entretanto, o crucial é a imagem que o interlocutor faz do outro. Daí, o contrato de comunicação regula o discurso dos sujeitos, sendo uma espécie de acordo entre as partes, mesmo que não seja de forma consciente, “(...) entre os interlocutores sobre cinco pontos: (a) os respectivos papeis sociointerativo; (b) as estratégias comunicativas a serem empregadas; (c) os conteúdos oportunos; (d) a variedade de língua utilizada; (e) as formas de discurso (tipos, gêneros e modos de organização) pertinentes." (AZEREDO, 2018, p.42)

Já o condicionamento discursivo, os textos, ao serem produzidos, revelam a sua finalidade, circunstâncias históricas e socioculturais, identidade do enunciador e do destinatário. Devido a isso, os textos possuem duas ordens de condicionamento discursivo, sendo: os espontâneos que atendem as situações imediatas e os planejados que atendem aos momentos não imediatos.

Quanto aos códigos, os textos são representados por códigos - sonoro, gráfico, gestual etc. O código é o conjunto de unidades que se transformam em textos para transmitir as informações.

O propósito comunicativo e modalidade enunciativa, segundo o autor, os textos são produzidos para serem entendidos por um ou mais destinatários. Toda interação verbal entre as pessoas tem um propósito comunicativo por parte de quem fala mediante um componente denominado modalidade. Esta revela a atitude do enunciador em relação ao destinatário.

Todo texto se define em modelo de composição apropriado a um determinado contexto, sendo que, esse modelo recebe o 
nome de gêneros textuais. Ele apresenta aspectos organizacionais, temáticos e estilísticos que os padronizam. Ele é uma das partes fundamentais do contrato de comunicação.

Nos modos de organização do discurso, os homens formam seus textos conforme suas motivações e necessidades. Inúmeros são os gêneros textuais, mesmo assim, eles se organizam internamente conforme os modos de organização: narração, descrição, exposição, argumentação e injunção.

A coerência e a coesão são elementos importantes na construção do texto, pois para um texto ter sentido, ele precisa ser compreendido pelo leitor. A coerência pode ser entendida como a articulação de ideias no decorrer do texto, enquanto que a coesão refere-se aos elos de ligação entre as frases, parágrafos e períodos de um texto.

Um texto pode possuir informações ocultas, causando muitas vezes, lacunas. Isto não quer dizer falha na comunicação, mas sim, estratégias da fala. Dessa forma, os sentidos pertencem a dois segmentos: pressupostos e os subentendidos. Pressuposto é quando a informação contida no texto dá margem para o leitor interpretar o que se quer dizer. Já o subentendido refere-se a uma informação que está nas entrelinhas do texto, isto é, o leitor compreende sem que esteja claro no texto.

Além dos sentidos, todo texto é uma cópia ou referência a outro. Nenhum texto é puro em informação. Isto recebe o nome de intertextualidade.

Os textos podem apresentar tanto rigidez quanto flexibilidade nas formas de expressão, pois o comportamento discursivo das pessoas representa a capacidade que elas têm para selecionar e organizar os seus discursos conforme as situações vivenciadas. Em função dessa seleção e avaliação do contexto, 
que os gêneros textuais e os registros linguísticos são escolhidos adequadamente.

O capítulo 4 Apontamentos para uma filosofia de ensino de língua o capítulo é iniciado com uma indagação "língua - um dom natural?". Então, para o autor, um sujeito ao falar parece não fazer esforço para isso. Há pessoas que acreditam que a língua é um dom prático. A língua que o sujeito fala é uma forma de atuar, conhecer e ser no mundo. A partir daí, a língua deixa de ser um dom e assume uma posição de escolhas e necessidades de criar.

Em cada situação de fala, interagimos com pessoas diferentes. É o contexto de fala que guia a conversa, ou seja, a língua utilizada. Em algumas situações, a conversa pode tomar um rumo imprevisível, enquanto, em outras, pode exigir normas mais rígidas, com atos comunicativos impessoais e previsíveis.

Qualquer ato comunicativo é uma forma de comportamento social. E a forma de língua utilizada revela a imagem que o interlocutor faz da situação, ou seja, ele que julga ser necessário utilizar ou não uma língua formal.

A língua que falamos nos distingue no universo dos seres humanos. A língua representa muito mais que um simples dom da natureza humana. Os atos comunicativos dos seres humanos são produzidos por meio de palavras e os significados da produção e recepção dependem de cada pessoa.

A interação entre as pessoas ocorre por meio de variados sinais como sonoro, palavra, gestos etc. A língua tem função social na vida cotidiana das pessoas.

Há vários critérios para definir uma língua como língua e são eles: - interacional ou sociocomunicativo - a língua como meio de interação entre as pessoas. É uma característica externa 
de uma língua. A função comunicativa é a concretização de várias propriedades da língua. Essas propriedades da língua passam por três critérios: cognitivo, estrutural e antropológico.

Sob o olhar da psicologia cognitiva, a língua funciona como um funil, ou seja, tudo que vivemos pode se tornar em um bate-papo. Em relação à estrutura, a língua funciona como um complexo sistema que rege a união da significação e significante na produção dos signos. Os significantes são os materiais sonoros ou gráficos e os significados são os conteúdos, as ideias. $\mathrm{O}$ significado e o significante resultam em signo linguístico. Uma palavra, uma frase ou um longo texto são signos. Sob o olhar da antropologia, a língua é inerente ao ser humano. Ela é um bem cultural. É por meio da língua que o homem conhece o mundo e desse saber que ele conversa com seus colegas. As três definições apresentam diferentes pontos de vista sobre a linguagem, mas são complementares.

Em relação ao ensino de língua materna, a relevância está no fato de que ninguém domina completamente sua língua. Por isso, a função de um professor de língua é desenvolver as competências necessárias para que um sujeito saiba operar corretamente com a língua. A língua não deve ser considerada em seu uso como certo ou errada, há opções de uso. Desse modo, Azeredo (2018, p.57) argumenta que "o importante é que os usuários se tornem aptos a perceber o vínculo funcional entre a finalidade da atividade comunicativa, a situação de uso, o perfil do texto e sua construção léxico-gramatical”.

Portanto, é função da escola, não exclusivamente, mas preferencialmente, desenvolver as competências e habilidades necessárias para que o ser adquira certos conhecimentos sobre a língua. 
No capítulo 5 "Sorria; você está sendo filmado" As estratégias do dizer, uma característica fundamental da comunicação do homem é poder dizer uma mesma coisa de várias formas diferentes com o mesmo objetivo e o sucesso do ato comunicativo dependerá das escolhas discursivas do interlocutor. $\mathrm{O}$ autor utiliza do exemplo muito comum de se ver em comércios como "Sorria. Você está sendo filmado" para explicar as estratégias de uso da linguagem. Tal frase, de forma educada, quer dizer ao cliente que ele deve se comportar adequadamente para não ter problemas. Também, utiliza da frase "Comporte-se adequadamente. Estamos de olho em você" para demonstrar que esta tem o mesmo sentido que a primeira, mas de forma deselegante, impositiva e bem direta. Como os homens se comunicam por meio de textos, eles demonstram o que são por causa de suas formas. As formas dos textos tem relação com as intenções e finalidade no ato comunicativo. $\mathrm{O}$ uso da palavra em qualquer situação do cotidiano se dá por meio do papel social que uma pessoa desempenha na sociedade. Esse papel que dá legitimidade ao que a pessoa diz.

E o que a gramática e a retórica tem haver com o mencionado acima. Conforme Azeredo (2018, p.71) “(...) a gramática é arte do bem construir a frase em benefício da clareza do pensamento, ao passo que a retórica é a arte de romper com as leis racionais da gramática em proveito do sentido que convém ao enunciador." Portanto, a gramática não existe sem a retórica e vice-versa. Podese dizer que há textos que prevalecem o teor lógico-gramatical, enquanto em outros, prevalecem os propósitos retóricos.

Em relação à leitura, o autor a denomina como meio de compreensão do mundo transformado em significados por meio de uma sequência de palavras e de discursos. O primeiro 
passo para entender tal sentido é reconhecer a relação entre as formas do discurso e os tipos de conhecimentos. Desse modo, ele distingue seis tipos de conhecimento: senso comum, religião, ciência, filosofia, humor e poética (= arte) divididos em dois discursos: construtores e desconstrutores.

O capítulo 6 Construção sintática e coesão lexical aborda a importância das expressões nominais como importante recurso de coesão lexical. As nominalizações anafóricas e catafóricas podem assumir funções no texto como de explicitar o ato de fala que se retoma (anafórico) ou se antecipar (catáfora). Esse recurso ilustra o que Patrick Charaudeau intitulou de "o modo enunciativo de organização do discurso" que pode ser visto com frequência nos textos notícia e artigo opinativo.

O capítulo 70 aposto e o intertexto explica o uso do aposto e do intertexto por meio dos textos. Para falar da intertextualidade baseia-se em um fragmento do romance da literatura brasileira do século XIX, Iracema, de José de Alencar e Macunaíma de Mário de Andrade. Aborda a relação entre eles, ou seja, o discurso de Alencar influenciou o discurso de Mário de Andrade. O autor quer mostrar que um texto nunca é puro das ideias de alguém. Então, ele cita a referência como um recurso importante que lembra a intertextualidade. Ela é efetivada por meio de nomes próprios, as descrições, pronomes etc. É nesse momento que o autor se reporta ao aposto, elemento importante na construção dela, isto porque Azeredo (2018, p.112) afirma que “(...) haja vista seu potencial de uso no modo argumentativo de organizar o discurso e suas possíveis associações com os gêneros textuais".

O capítulo 8 Leitura e escrita na língua materna: tarefa interdisciplinar o autor argumenta que, na tradição escolar brasileira, a expressão "saber português" significa ter o 
domínio de duas competências: o da norma padrão e a aptidão para identificar os fatos da língua. Qualquer língua natural apresenta variações de usos que correspondem tanto aos modos de expressão quanto gramaticais e de vocabulário. Por isso, a língua tem uma função social, pois tais diferenças servem como forma de compreensão entre os usuários de uma língua e de manifestação de identidade social e cultural. Além disso, cada sujeito sabe usar sua língua para suprir suas necessidades comunicativas regulares e do cotidiano.

O homem vive em um universo de significados criados por ele tanto social quanto histórico ou cultural. Ele expressa-se por meio de múltiplas formas de simbolização como palavra, gesto, desenho, pintura, música etc. Com isso, o uso da língua está relacionado ao contexto situacional.

O autor baseia-se no Parâmetro Curricular Nacional de Língua Portuguesa para explicar que a competência a que o documento se refere não pode ser tratada como objetivo de uma única área de conhecimento - no caso, a língua portuguesa e suas respectivas literaturas -, pois esse é o objetivo de toda a educação fundamental. A partir daí, ele ressalta que o texto é a base para o ensino de língua. Por isso, ele defende que as habilidades de leitura e escrita devem ser desenvolvidas em todas as disciplinas, pois todas trabalham com textos. Compete a todos os professores alertar e orientar seus alunos para a adequação da expressão verbal mesmo que seja referente à propriedade $\mathrm{e}$ característica formal do gênero textual, a sua formulação e a informação presente no texto.

O capítulo 9 Rosa, Rosae: uma estilística da irreverência faz referência ao conto "Rosa, Rosa, Rosae" pertencente ao livro A morte de D. J. em Paris do escritor mineiro Roberto 
Drummond para mostrar as faces de uma língua, pois o autor não usa nem a língua padrão nem a variação linguística. Ele cria uma linguagem que Azeredo chama de idioleto em que mistura comicamente o português com o latim, tendo o uso excessivo de desinências latinas.

A língua possui duas faces: estrutural que se refere aos fonemas, morfemas, palavras, nomes, tonicidade, entoação e entre outros e a institucional que se refere às relações entre a língua como instituição social e os sujeitos. Assim, demonstra que o Latim é uma face institucional pelo valor que representa, isto é, quem sabia falar o idioma Latim era considerada uma pessoa culta.

O capítulo 10 De pedras e palavras: o atrito como estética elegeu o escritor João Cabral de Melo Neto para falar do atrito, visto que o autor literário em suas obras usa o termo pedra. Ela representa o maior símbolo do atrito, pois este tanto cria quanto constrói.

O atrito tem duas funções básicas: banir da superfície dos objetos e situações o que tira a sua força e o recobre impedindo1he de mostrar realmente sua face. E João Cabral de Melo Neto demonstra muito bem isto por meio do contraste entre exterioridade e interioridade, utilizando em sua poesia muitos substantivos, verbos e adjetivos que criam conflitos entre os dois extremos.

O atrito assume três feições conforme o que ele causa: transitiva, quando um objeto comunica a força cortante do outro; passiva, quando um objeto compreende a agudeza do outro; recíproca, quando a junção de duas ou mais entidade resultam em ferimento duplo.

No capítulo 11 Usos e representações da palavra nas 
crônicas de Carlos Drummond de Andrade, o autor utiliza as crônicas, do escritor Carlos Drummond de Andrade, Correio da Manhã e do Jornal do Brasil para demonstrar a pluralidade de usos do português brasileiro. A crônica se firmou no século XX como gênero de experiência na Literatura pelos escritores literários, tendo como suporte, os jornais da época. Drummond aproveitou da elasticidade do gênero para exprimir o desconcerto da existência.

A palavra, como forma de manifestação, representa muito mais que um simples instrumento de comunicação. A linguagem exerce múltipla tarefa. Drummond deixa claro em suas crônicas que a palavra representa manifestação cultural, histórica, sentimental, identidade etc. A Literatura tem um papel fundamental nisso, porque ela possibilita a interpretação da realidade ou até mesmo a invenção do real. A palavra na Literatura é um objeto. É um local onde o mundo converte em sentido para o homem.

No capítulo 12 Entre a gaiola e o céu azul: o que é o mundo? o autor inicia abordando brevemente as obras de Machado de Assis que são narrativas que têm intrigas e despertam o interesse no leitor. As narrativas dele não possuem vilões e heróis como as pessoas estão acostumadas a ler. As personagens de Machado de Assis são pessoas comuns que protagonizam conflitos provenientes da difícil tarefa de harmonizar os interesses particulares e os códigos que regem a vida social. Dessa forma, o leitor buscará o desfecho da história, podendo presenciar revelações sobre o perfil psicológico dos personagens sob um contexto histórico-social específico.

Um conto de fantasia de Machado de Assis que acompanha o Azeredo em suas salas de aulas é "Ideias de canário". Ele foi 
publicado na Gazeta de Notícias (1895) e mais adiante incluso no volume Páginas recolhidas (1899). Esse conto é uma espécie de parábola da verdade. Por meio de seus personagens, é notável um eco do Livro VII de A República, em que Platão narra $O$ mito da caverna. Então, o autor fará uma leitura levantando aspectos que interligam forma e sentido, demonstrando a intertextualidade entre Ideias de canário e $O$ mito da caverna.

A parábola de "Ideias de canário" com o "Mito da caverna" se encontram no momento em que a história recorre a uma tese filosófica sobre conceito de realidade. Azeredo ressalta que o primeiro promove o triunfo delas cinicamente. Na parábola de Machado de Assis prevalece a representação literária, mas ao mesmo tempo, descontrói outros gêneros, pois o canário ganha participação na história mediante o recurso da personificação. Mas, é diferente das fábulas em que os animais ganham atitudes e comportamentos de seres humanos. No decorrer do texto, o narrador tem cuidado para que o leitor não confunda com a fábula. Afinal, é um conto que finge ser outro gênero.

Ideias de canário organiza-se em três segmentos narrativos: o $1^{\circ}$ do início até a primeira definição de mundo dada pelo canário; o $2^{\circ}$ daí até a segunda definição de mundo; o $3^{\circ}$ é o restante do conto. Os três segmentos trava o diálogo entre o canário e o senhor Macedo. O tempo no conto é assinalado duplamente, sendo por um momento de troca de espaços em busca da liberdade e o outro voltado para o uso dos verbos.

Em relação ao ponto vista, Azeredo explica que há dois narradores: um narrador com participação rápida e o outro como personagem representado por Macedo. O narrador 1 prepara o leitor de que ele lerá uma história fantasiosa, alegórica. Já o narrador 2 tenta em seu relato a aproximação com o verossímil. 
Outro recurso utilizado pelo narrador 2 é o metadiscurso, deixando claro que pode haver diferença entre a narração e a experiência do fato. Também, o personagem Macedo evita transparecer que o canário falava a língua dos homens.

Machado de Assis utiliza o cientificismo em suas obras com ironia e até sarcasmo. Macedo é o porta-voz do cientificismo e como narrador 2 utiliza o tom forte da verossimilhança.

O canário e Macedo são personagens antagônicas e diferentes. Canário é apenas a outra face de Macedo. Assim, o diálogo gira em torno do fingimento. Macedo tem dupla face: uma que apresenta o cientificismo da época e outra escarnece da arrogância cientificista. $\mathrm{O}$ dualismo do ponto de vista pertencente à mesma pessoa, alimenta o conflito de Macedo, que o adoece. Macedo, dentro da perspectiva de seu tempo, opõe-se ao presente e ao passado, olhando para o futuro. O canário é quem muda objetivamente, mas sua visão de mundo permanece inalterada. Depois, Macedo e o canário invertem seus papeis. No final, o canário define seu mundo como espaço azul e infinito e Macedo, movido pelo espírito de negociação, adota o segundo conceito de mundo formulado pelo canário.

Quanto aos contrates constitutivos da narração, Azeredo apresenta: canário e Macedo, caos e ordem, tempo e espaço, loucura e sanidade.

Para finalizar, o autor faz um arremate da representação da história Ideias de canário de Machado de Assis com base no $O$ mito da caverna. Ela é uma espécie de parábola semi-didática onde o conflito da personalidade de Macedo é dividido entre ele e o canário, sendo: um cientificismo e a outra a experiência do dia a dia. Machado de Assis mistura os gêneros textuais para falar da vivência do canário e de Macedo. A história apresentada 
aborda o processo de um pesquisador que acaba se tornando um paciente de seu próprio objeto. Portanto, o autor sugere que Ideias de um canário é uma leitura que serve de exemplo para mostrar que a realidade humana é uma experiência simbólica, constantemente recriada elas próprias interpretações.

A obra resenhada apresenta informações importantes sobre o ensino de língua materna que tem o texto como base, pois ele não é um amontoado de palavras e sim uma unidade de sentido. Além disso, as pessoas se comunicam por meio dele. Em concordância, a autora Albertina Rossi em seu livro "Linguística Textual e ensino de Língua Portuguesa" defende que, para o aluno desenvolver as habilidades de ler, escrever, ouvir e falar, é fundamental um ensino de língua voltado para a diversidade textual que contemple as situações reais de comunicação. Isto porque, hoje, vivemos em uma sociedade letrada, isto é, exige-se que o indivíduo saiba tanto ler quanto escrever proficientemente. Além do mais, em um processo de interação com o outro, a comunicação clara e precisa é fundamental. Outro ponto interessante é a linguagem clara e simples que facilita a compreensão do assunto abordado. A estrutura da obra, que apesar de ser dividida em capítulos, todos perpassam pelo ensino de língua, tendo o texto como objeto e objetivo do ensino da língua, despertando assim, uma reflexão, no leitor, sobre qual e como ensinar os alunos a Língua Portuguesa, de forma que, realmente sejam capazes de desenvolver as habilidades de leitura e escrita. Assim, a obra traz importante contribuição para os estudos sobre o ensino de língua.

A obra é recomendada para os estudantes de graduação em Letras, professores de língua materna, estudantes em formação continuada ou qualquer pessoa que tenha interesse no assunto 
que aborda o ensino de língua materna.

\section{Referências}

BRASIL. Lei $\mathbf{n}^{0}$ 5.692, de 11 de agosto de 1971: fixa diretrizes e bases para o ensino de $1^{\circ}$ e $2^{\circ}$ graus e dá outras providências. Diário Oficial da União, Brasília (DF), 12 ago. 1971.

GERALDI, Wanderlei. Linguagem e ensino: exercícios de militância e divulgação. São Paulo: Mercado de Letras, 1996.

MACHADO DE ASSIS, J. M. Obra completa. Vol. II. Rio de Janeiro: Nova Aguilar, 1994.

ROSSI, Albertina. Linguística textual e ensino de língua portuguesa. Curitiba: InterSAberes, 2015. 